\title{
Evaluating the Effect of Plastomer Modified Asphalt Mixture on High/Low Temperature Performance
}

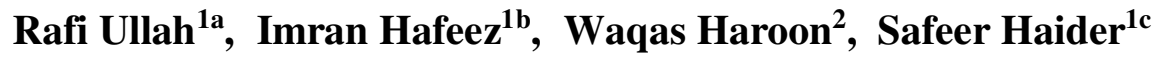 \\ RECEIVED ON 15.07.2019, ACCEPTED ON 16.12.2019
}

\begin{abstract}
Asphalt pavement's surfaces deteriorate over time due to combined effect of traffic and surrounding environment. Fatigue and rutting are the major distresses which cause failures in flexible pavements. Different temperature control computer operated equipment's are being used worldwide to predict the performance of asphalt mixtures at approximately same condition to those in-service pavements. Similarly, different types of polymers such as elastomer and thermoplastic have been used all over the world in Hot Mix Asphalt (HMA) for the improvement of asphalt mixtures. But little attention has been taken to evaluate the effect of plastomer on hot mix asphalt performance. Moreover, the initial cost of elastomer is higher than other types of polymers such as plastomer. The aim of this research study is to check the effect of various plastomers on high/low temperature performance of asphalt mixture. Four performance tests like Cooper wheel tracker, dynamic modulus, uniaxial repeated load and four-point bending beam test are used to evaluate the effect of different type of plastomers such as polyethylene terephthalate, high density and low density polyethylene with limestone aggregate quarry and 60/70 pen grade asphalt binder. This research study concludes that plastomer increases flexibility and hardness of asphalt mixtures and improves the rut resistance, dynamic modulus and fatigue life of asphalt mixtures. Plastomer modification shows significant benefits as compared to neat binder for high/low temperature performance. Moreover, it can be concluded that plastomer provides an efficient and economical blend of asphalt mixture.
\end{abstract}

Keywords: Asphalt Mixture, Plastomer, Modifiers, Fatigue Life, Rut Resistance

\section{INTRODUCTION}

$\mathrm{R}$ utting and fatigue cracking are the normally occurring distresses in asphalt pavements. Bitumen is a material which is used for the construction of asphalt pavements and it has viscoelastic and thermoplastic properties, i.e. it behaves as an elastic solid at low temperature and under rapidly moving traffic conditions, similarly it behaves as viscous fluid at high temperature and under slow moving traffic conditions $[1,2]$. So asphalt mixture which is used for road construction has specific parameters and temperature negatively influences these parameters and decreases the lifespan of pavement structure [3]. Rutting (Permanent deformation) and cracking (fatigue) are the major distresses which deteriorate the pavement at high and intermediate temperature. Permanent deformation and cracking due to fracture damage are the distresses in asphalt pavement which appear in the wheel track along the driving direction [4]. Due to increase of temperature in summer season and heavily loaded vehicles especially slow moving vehicles, the effect of rutting increases significantly. Flexible pavements undergo permanent deformation due to heavy and channelized traffic loading. Annihilation of flexible pavement due to occurrence of rutting in parallel direction of moving traffic may cause many traffic

\footnotetext{
${ }^{1}$ Department of Civil Engineering, University of Engineering and Technology, Taxila, Pakistan. Email: ${ }^{a}$ rafiullah138@yahoo.com (Corresponding Author), ${ }^{\text {bimran.hafeez@uettaxila.edu.pk, }}$ csafeerhaider112@hotmail.com

${ }^{2}$ Department of Civil Engineering, International Islamic University Islamabad. Email: waqas.haroon @iiu.edu.pk This is an open access article published by Mehran University of Engineering and Technology, Jamshoro under CC BY 4.0 International License.
} 
accidents if the rut depth and area are beyond the limited range. To overcome the problem of weak asphalt mixes, it is necessary to enhance asphalt properties to control rutting and fatigue cracking. Preparation of high performance asphalt mixture with increased service life is essential. So, modification of asphalt is important to improve the performance of bituminous layer against heavy traffic load and harsh climatic conditions.

Asphalt mixtures with additives such as thermoplastic, elastomer and plastomer are usually used to change the phase composition and improve the engineering properties of asphalt to bear the heavily loaded traffic in slow and rapidly moving traffic conditions. In this research study different plastomer modifiers are used to improve hot mix asphalt performance against fatigue cracking as well as permanent deformation.

Modified asphalt can improve the properties of asphalt mixture. Most commonly used polymers are StyreneButadiene-Rubber (SBR), Styrene-Butadiene-Styrene (SBS), Polyethylene and Ethylene Vinyl Acetate (EVA). These polymers enhance the performance of asphalt mixture against rutting, fatigue cracking and moisture damaging [5, 6]. SBS acts as an elastoplastomeric polymer and can increase the dynamic performance of asphalt mixture under varying load conditions $[7,8]$. The basic function of elastomers is to improve rheological and chemical properties of bituminous binder [9]. Similarly, plastomers are used in asphalt mixture for enhancement of properties of asphalt mixture [10]. Plastomers such as waste plastic are introduced into asphalt mixture which increase the performance properties of asphalt concrete mixture and also increase the pavement service life [11, 12]. Use of waste plastic in asphalt concrete mixture may increase pavement service life 2.81 times [13] and may reduce the quantity of asphalt binder and consequently may reduce the total cost of whole project [14]. Other type of plastomer such as plastic scrap is used in asphalt for performance improvement. Addition of plastic scrap shows greater indirect tensile strength, higher air void content, reduced moisture damage and a $2 \%$ decrease in the ratio of conserved tensile strength [15]. Crumb rubber and polymer modified asphalt mixtures can be used for a specific condition in extreme climatic condition areas. Some enhanced properties can be achieved e.g. more resistance against deformation at high temperature, less susceptible due to change in temperature, increase in long term resistance properties, improvement of compatibility between aggregate and bitumen, increase in fatigue life and prevention of rutting and cracking [16]. Polymer modified asphalt mixtures have been used for road construction [17, 18]. The modification of asphalt mixture with waste plastic carries advantages of improvement in conventional binder performance in a cheap way and also with utilization of waste plastic [19]. Similarly, when we utilize low density polyethylene in conventional mixture, it decreases the penetration and phase angle, increases the complex modulus, softening point, and rotational viscosity which indicate the high/low temperature rheological characteristics of the asphalt mixture [20]. When we utilize ground tire rubber with low density polyethylene, it increases the conventional and rheological properties of binders [21-23]. Similarly, utilization of motor oil and waste polymers in bitumen have a good effect on high/low temperature performance and enhance the rut resistance and fatigue life of asphalt mixture [24]. [25] reported that modification of asphalt mixture with high density polyethylene reduces the temperature and moisture susceptibility of the mixture. Fatigue performance of asphalt mixture can be improved by using StyreneButadiene-Rubber (SBR) [26-27].

In developing an investigational testing method for evaluating the characterization of HMA mixes, most researchers have used different latest techniques for performance testing by using different types of modifiers and study the individual effect of each modifier on HMA performance. But previous research studies have not deliberated more about the effect of plastomer on asphalt mixture and have not described the comparative effect of different plastomers i.e. lowdensity polyethylene, high density polyethylene and polyethylene terephthalate on asphalt mixture.

The primary objective of this research study is to evaluate the effect of plastomer on HMA and determination of optimized doses of plastomer for best results. Furthermore, this research study evaluates the comparative effect of different types of plastomer on HMA performance. 


\section{RESEARCH METHODOLOGY}

Research methodology is divided into three phases shown in Fig. 1. Phase-I consists of selection of material i.e. aggregate, bitumen and plastomer. Aggregate is taken from Margallah quarry which has been most frequently used aggregate in HMA mixes throughout the Pakistan. Bitumen with 60/70 penetration grade used in this study is taken from National Oil Refinery (NRL), as this is most commonly used bitumen in road construction material in Pakistan. The plastomers such as Low Density Polyethylene (LDPE), High Density Polyethylene (HDPE) and Polyethylene Terephthalate (PET) are taken from local sources. Phase-II consists of mix design preparation. Marshal method of mix design as per ASTM 1559 is taken on to get Optimum Bitumen content $(\mathrm{OBC})$ and volumetric properties of mixture.

Phase-III consists of performance testing of asphalt mixture. Four HMA performance tests such as Cooper
Wheel Tracker Test (CWTT), Dynamic Modulus (DM) test, Four-Point Bending Beam Test (FPBB), Uniaxial Repeated Load Permanent Deformation (URLPD) test are selected to study the effect of plastomers on HMA performance at high/low temperature. Physical and chemical properties of material are also conducted according to standard conditions.

\subsection{Aggregate}

Aggregate used for bituminous mixture is taken from local quarry i.e. Margallah which contains limestone minerals. It is the best mechanically fractured aggregate producing quarry of Pakistan. Physical and Mechanical properties of selected aggregates are measured according to standard specification of AASHTO, ASTM and BS. Engineering properties of aggregates have been summarized in Table 1 . Rounded and river bed particles are not used in this research study.

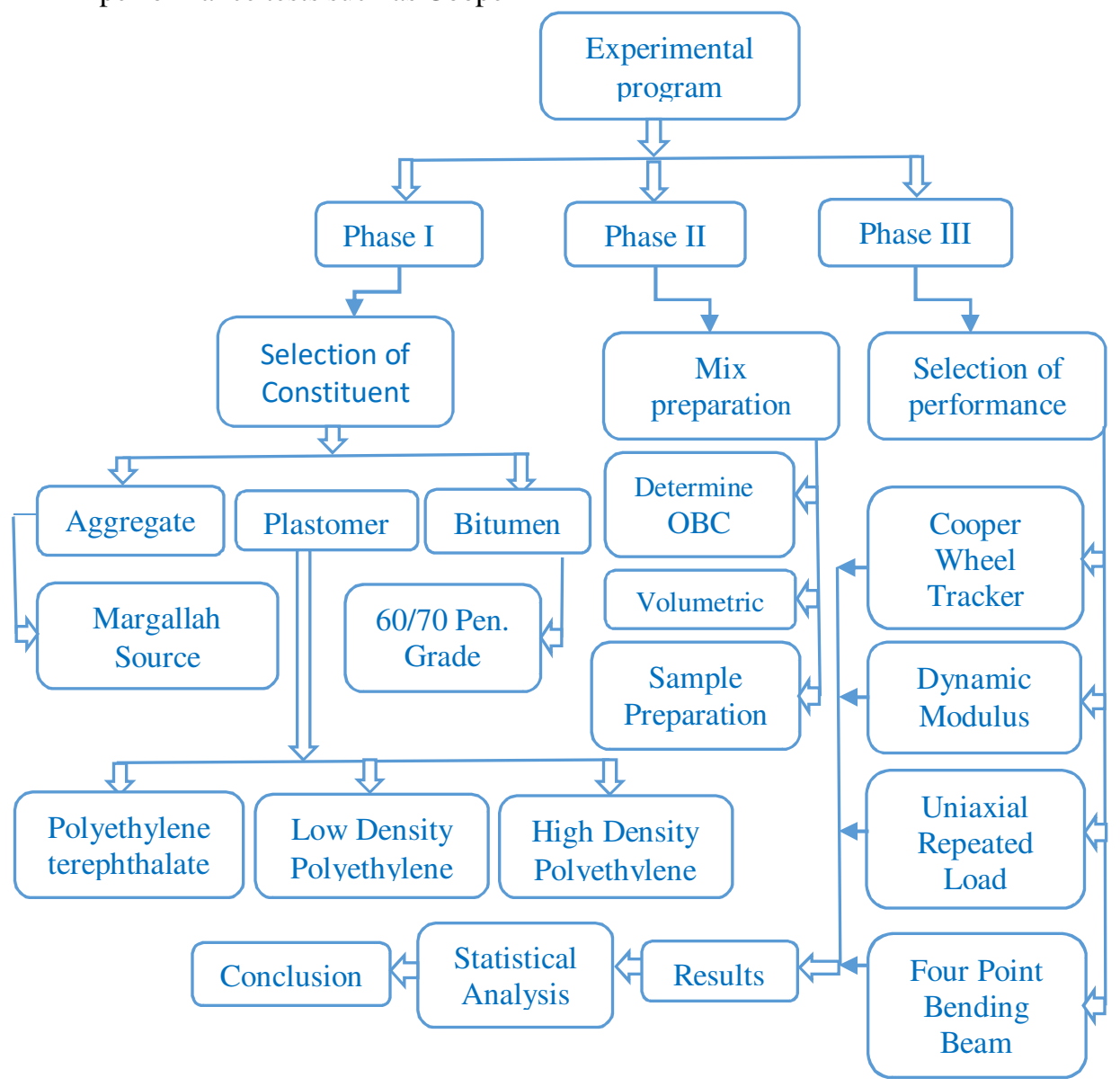

Fig. 1: Flowchart for Experimental Program 


\begin{tabular}{|c|c|c|c|c|}
\hline \multicolumn{5}{|c|}{ Table 1: Properties of Tested Aggregate } \\
\hline Sr. No. & Test Title & Standard & Calcium Carbonate & Specification Limit \\
\hline 1 & Fractured Particles (\%) & ASTM D 5821 & 100 & $90(\min )$ \\
\hline 2 & Flakiness Index (\%) & BS 812.108 & 5.9 & $10(\mathrm{max})$ \\
\hline 3 & Elongation Index (\%) & BS 812.109 & 2.4 & $10(\mathrm{max})$ \\
\hline 4 & Sand Equivalent Value (\%) & ASTM D 2419 & 75 & $50(\mathrm{~min})$ \\
\hline 5 & Los Angeles abrasion Value (\%) & ASTM C 131 & 25 & $30(\mathrm{max})$ \\
\hline 6 & Water absorption (\%) & ASTM C 127 & 1.03 & $2(\max )$ \\
\hline 7 & Soundness (Coarse) (\%) & ASTM C 88 & 8 & $8(\max )$ \\
\hline 8 & Soundness (Fine) (\%) & ASTM C 88 & 4.6 & $8(\max )$ \\
\hline
\end{tabular}

Volumetric properties of asphalt mixture mostly depend on aggregate source, their properties and selected aggregate gradation. Packing characteristics of selected aggregates are affected by such characteristics and skeleton. The unit weight of selected coarse aggregate has been utilized in the Bailey method by introducing three ratios to improve packing characteristic. The amount of aggregate which fills a unit volume without application of compaction effort is defined as loose unit volume of aggregate.
This denotes interlocking of coarse aggregate without compaction effort. Bailey method offers better interlocking characteristics as compared to conventional gradation [18]. For the purpose of getting relatively better interlocking of aggregate, Bailey gradation method is used in this research study. Tabular and graphical representation of aggregate gradation is reported in Table 2 and Fig. 2 respectively.

\begin{tabular}{|c|c|c|c|c|}
\hline \multicolumn{5}{|c|}{ Table 2: Adopted Bailey Method of Gradation } \\
\cline { 1 - 2 } Inch & $\mathrm{mm}$ & $\begin{array}{c}\text { Bailey passing } \\
(\%)\end{array}$ & $\begin{array}{c}\text { Class B Lower } \\
\text { passing (\%) }\end{array}$ & $\begin{array}{c}\text { Class B Upper } \\
\text { passing (\%) }\end{array}$ \\
\hline $3 / 4$ & 19 & 100 & 100 & 100 \\
\hline $1 / 2$ & 12.5 & 77.4 & 90 & 75 \\
\hline $3 / 8$ & 9.5 & 64.1 & 80 & 60 \\
\hline$\# 4$ & 4.75 & 39.9 & 60 & 40 \\
\hline$\# 8$ & 2.36 & 27.7 & 40 & 20 \\
\hline$\# 16$ & 1.18 & 16.6 & 27 & 12 \\
\hline$\# 30$ & 0.6 & 10.4 & 19 & 8 \\
\hline$\# 50$ & 0.3 & 8.1 & 15 & 5 \\
\hline$\# 100$ & 0.15 & 5.7 & 11 & 3 \\
\hline$\# 200$ & 0.075 & 4.1 & 8 & \\
\hline
\end{tabular}

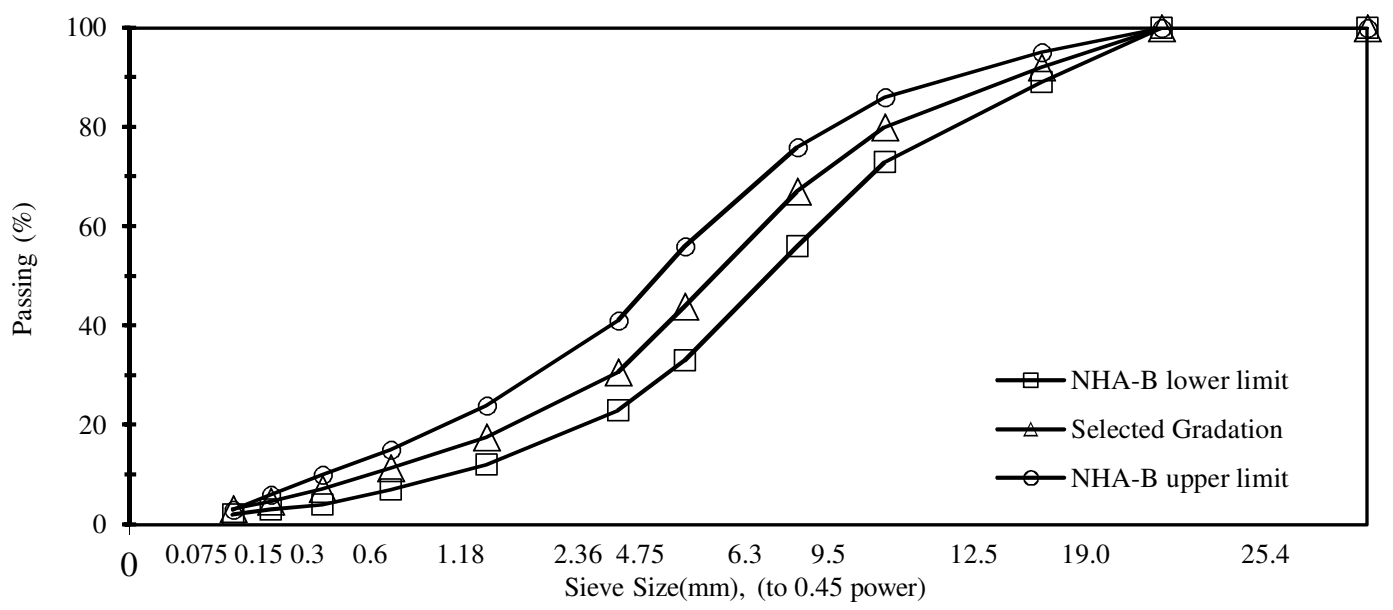

Fig. 2: Selected Aggregate Gradation 


\subsection{Bitumen}

A $60 / 70$ penetration grade bitumen containing paraffinic as well as asphaltic hydrocarbon chain with Performance Grade (PG) 58-22 is selected in this research study. The basic properties are given in Table 3.

RTFO aged binders are used for frequency sweep test to determine the time and temperature dependency of bitumen by using Dynamic Shear Rheometer (DSR). A range of frequency from 0.1 to 10 and temperature from 22 to 82 is used for development of master curve. Master curve is plotted between reduced frequencies taken on abscissa and complex shear modulus $\left(G^{*}\right)$ taken on ordinate by using sigmoidal parameters. Master curve and sigmoidal coefficient has been presented in Fig. 3.

\subsection{Modifiers}

Three different types of plastomer have been used in this research study i.e. Low-Density Polyethylene (LDPE), High Density Polyethylene (HDPE) and Polyethylene Terephthalate (PET) as shown in the Fig.4 (a-c).

These plastomers have been taken from locally available resources. The modification of asphalt mixture with plastomer improves the permanent deformation resistance and dynamic modulus of asphalt mixture [19]. Design optimum values of LDPE, HDPE and PET are 9\%, 8.7\% and 8.5\% (by wt. of bitumen), respectively. Design optimum values of modifiers are obtained by their performance evaluation based on Marshal Stability test. Some important properties of modifiers are given in Table 4.

\begin{tabular}{|c|c|c|c|c|}
\hline \multicolumn{5}{|c|}{ Table 3: Properties of Control Binder } \\
\hline Sr. No. & Test Title & Standard & $\begin{array}{c}\text { Bitumen type (Pen. } \\
60 / 70)\end{array}$ & Specification Limit \\
\hline 1 & $\begin{array}{c}\text { Penetration at } 25{ }^{\circ} \mathrm{C} \\
(1 / 10 \text { th of } \mathrm{mm})\end{array}$ & $\begin{array}{c}\text { ASTM } \\
\text { D 5 }\end{array}$ & 68 & - \\
\hline 2 & Softening Point $\left({ }^{\circ} \mathrm{C}\right)$ & $\begin{array}{c}\text { ASTM } \\
\text { D 36 }\end{array}$ & 47 & - \\
\hline 3 & Ductility $(\mathrm{cm})$ & ASTM C 88 & 100 & $100(\mathrm{~min})$ \\
\hline 4 & Flash and fire point $\left({ }^{\circ} \mathrm{C}\right)$ & ASTM C 142 & 292 & $232(\mathrm{~min})$ \\
\hline
\end{tabular}

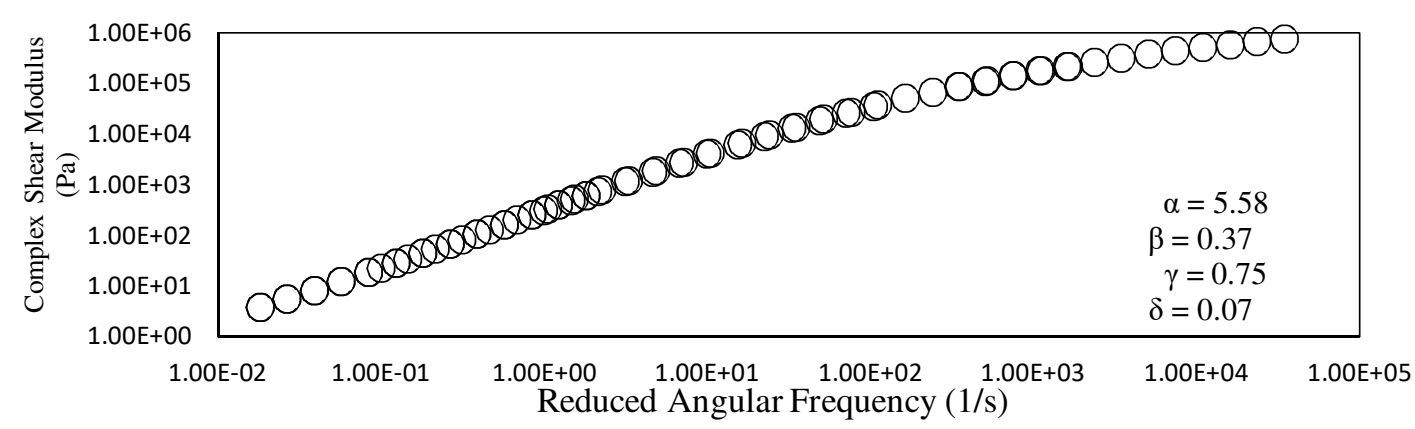

Fig. 3: Master Curve of PG 58-22 Penetration Grade Bitumen

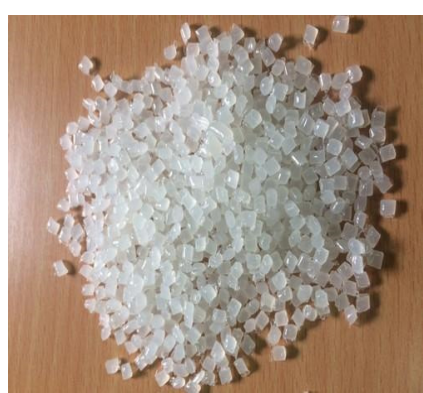

Fig. 4(a): LDPE

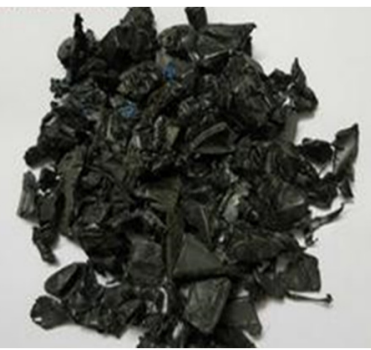

Fig. 4(b): HDPE

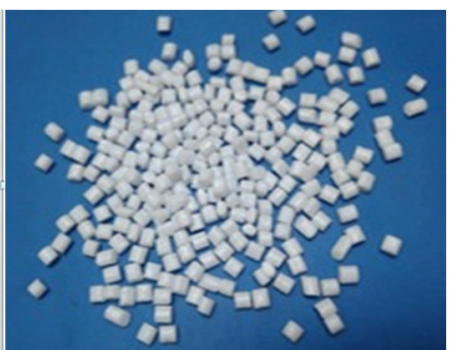

Fig. 4(c): PET 


\begin{tabular}{|c|c|c|c|c|}
\hline \multicolumn{5}{|c|}{ Table 4: Properties of Modifiers [20] } \\
\hline Property Name & Standard & $\begin{array}{c}\text { Low density } \\
\text { Polyethylene } \\
\text { (LDPE) }\end{array}$ & $\begin{array}{c}\text { High density } \\
\text { Polyethylene } \\
\text { (HDPE) }\end{array}$ & $\begin{array}{c}\text { Polyethylene } \\
\text { Terephthalate } \\
\text { (PET) }\end{array}$ \\
\hline $\begin{array}{c}\text { Thermal Conductivity } \\
\left(\mathrm{W} \mathrm{m}^{-1} \mathrm{~K}^{-1}\right)\end{array}$ & $\begin{array}{c}\text { ASTM } \\
\text { E1952 }\end{array}$ & 0.34 & $0.45-0.53$ & $0.16-0.4$ \\
\hline $\begin{array}{c}\text { Specific Heat } \\
\left(\mathrm{JK}^{-1} \mathrm{Kg}^{-1}\right)\end{array}$ & $\begin{array}{c}\text { ASTM } \\
\text { E1269 }\end{array}$ & $1900-2300$ & 1900 & $1200-1355$ \\
\hline Specific gravity & $\begin{array}{c}\text { ASTM } \\
\text { D891 }\end{array}$ & $0.910-0.935$ & $0.941-0.975$ & 1.45 \\
\hline Melting Point $\left({ }^{\circ} \mathrm{C}\right)$ & $\begin{array}{c}\text { ASTM } \\
\text { D1519 }\end{array}$ & $105-115$ & $120-185$ & $>250$ \\
\hline Tensile strength (psi) & ASTM D638 & $600-2,300$ & $3,100-5,550$ & $8,000-10900$ \\
\hline Density (Ib/cu in) & ASTM D792 & 0.0329 & 0.0344 & 0.0506 \\
\hline Water Absorption $(\%)$ & $\begin{array}{c}\text { ASTM } \\
\text { D570 }\end{array}$ & $<0.01$ & $<0.01$ & 0.17 \\
\hline
\end{tabular}

The two methods of mixing are normally used for mixing of selected modifiers or additives into asphalt mixture i.e. dry method and wet method. In this study, dry method of mixing has been used and modifiers are blended with aggregate prior to addition of bitumen. [21].

After attaining $180 \pm 5^{\circ} \mathrm{C}$ temperature of aggregate, polyethylene is mixed at design quantity. After that temperature is allowed to dropdown that is $160^{\circ} \mathrm{C}$ to avoid aging of asphalt binder. Then bitumen is added into the aggregate.

\subsection{Sample Preparation}

Marshal method of mix design is adopted at $4 \%$ air voids for optimization and prepare $10.2 \times 6.3 \mathrm{~cm}$ test specimen to get optimum bitumen content (OBC). Specific gravities and volumetric analysis are also conducted on design optimum bitumen content (OBC). Design volumetric parameters for each mixture type are summarized in Table 5.

Based on optimum asphalt content, the samples are prepared for performance testing. Super pave gyratory compacted samples, (with $150 \mathrm{~mm}$ diameter) by adopting procedure stipulated in AASHTO PP 35, sre prepared for Cooper wheel tracker, uniaxial repeated load and dynamic modulus test. Slabs (with $50 \mathrm{~mm}$ thickness) are prepared at $6 \pm 0.5 \%$ air voids (AV) by using roller compactor for four-point bending

\begin{tabular}{|c|c|c|c|c|}
\hline \multicolumn{4}{|c|}{ Table 5: Volumetric Properties Of Aggregate } \\
\hline Modifiers & Gsb & VA & VMA & VFA \\
\hline Standard & $\begin{array}{c}\text { T-84 } \\
\text { T-85 }\end{array}$ & - & $\begin{array}{c}\text { ASTM } \\
\text { D6995 }\end{array}$ & - \\
\hline $\begin{array}{c}\text { Specification } \\
\text { Limit }\end{array}$ & $2.4-2.9$ & 04 to 07 & $\begin{array}{c}14 \\
\text { (Minimum) }\end{array}$ & $65-75$ \\
\hline $\begin{array}{c}\text { Conventional } \\
\text { Mix }\end{array}$ & \multirow{2}{*}{2.65} & 6.1 & 15.53 & 60.95 \\
\cline { 1 - 3 } & & 6.2 & 16.80 & 63.38 \\
\cline { 1 - 3 } Modified Mix & $\begin{array}{c}\text { HDPE } \\
\text { Modified Mix }\end{array}$ & 6.1 & 16.43 & 62.73 \\
\cline { 1 - 3 } $\begin{array}{c}\text { PET Modified } \\
\text { Mix }\end{array}$ & 6.4 & 16.47 & 61.41 \\
\hline
\end{tabular}

beam test. The mixing and compaction temperature js maintained at $160 \pm 3^{\circ} \mathrm{C}$ and $150 \pm 2^{\circ} \mathrm{C}$, respectively. Approximately $7 \mathrm{~kg}$ sample having $150 \mathrm{~mm}$ diameter is used for performance testing. At the end of compaction process, the samples have been kept for minimum three hours to cool down at room temperature. Four performance tests (CWTT, DM, URLPD and FPBB) were carried out and results obtained from these tests are used for analysis. For dynamic modulus testing, cylindrical specimen of $100 \mathrm{~mm}$ diameter were extracted from $150 \mathrm{~mm}$ diameter super pave gyratory compacted specimen in accordance with AASHTO TP 62. For wheel tracker test, super pave gyratory compacted specimen cut into two pieces and uncut face was used for testing. For Uniaxial repeated load testing, cylindrical specimens were used with $150 \mathrm{~mm}$ diameter and $75 \mathrm{~mm}$ in height. For four-point bending beam test, a slab of $50 \mathrm{~mm}$ thickness was made with roller compacter and Mehran University Research Journal of Engineering and Technology, Vol. 40, No.3, July 2021 [p-ISSN: 0254-7821, e-ISSN: 2413-7219] 


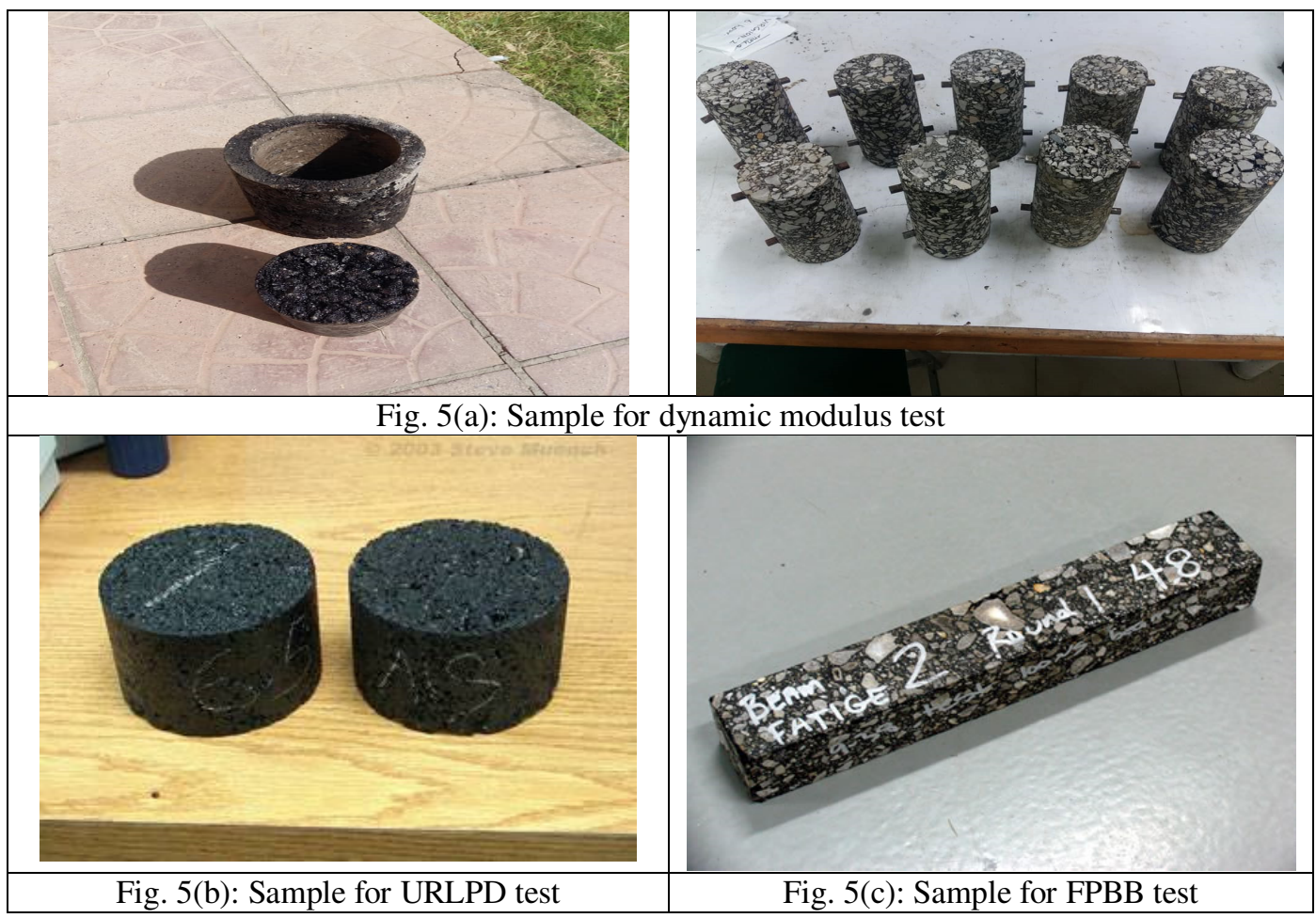

\begin{tabular}{|c|c|c|c|}
\hline \multicolumn{4}{|c|}{ Table 6: Test description and specimen sizes } \\
\hline Test Description & Machine used & $\begin{array}{c}\text { Sample } \\
\text { dimension/Size }\end{array}$ & Air voids (\%) \\
\hline $\begin{array}{c}\text { Cooper Wheel Tracker Test (CWTT) } \\
\text { (EN 12697) }\end{array}$ & $\begin{array}{c}\text { Cooper Wheel Tracker } \\
\text { Tester Diameter 150mm } \\
\bullet \text { Height 50mm }\end{array}$ & 6.02 \\
\hline $\begin{array}{c}\text { Uniaxial Repeated Load Permanent } \\
\text { Deformation Test (URLPD) }\end{array}$ & $\begin{array}{c}\text { Universal Testing } \\
\text { Machine (UTM-5P) }\end{array}$ & $\begin{array}{c}\bullet \text { Diameter 150mm } \\
\bullet \text { Height 75mm }\end{array}$ & 5.8 \\
\hline $\begin{array}{c}\text { Dynamic Modulus Test (DM) } \\
\text { (AASHTO TP 62) }\end{array}$ & Cooper NU-14 & $\begin{array}{l}\bullet \text { Diameter 100mm } \\
\bullet \text { Height 150mm }\end{array}$ & 5.9 \\
\hline $\begin{array}{c}\text { Four Point Bending Beam (FPBB) } \\
\text { (AASHTO T 321) }\end{array}$ & Cooper NU-14 & $\bullet(380 x 63 \times 50) \mathrm{mm}$ & 6.05 \\
\hline
\end{tabular}

fabricated into required dimension. Different used samples are shown in the Fig. 5 (a-c).

Four performance tests (CWTT, DM, URLPD, FPBB) were carried out and results obtained from these tests were used for analysis. Description of test and dimensions of used specimen are given in Table 6.

\section{RESULTS AND DISCUSSION}

\subsection{Rut Performance of Mixes}

The rut performance of neat and modified asphalt mixtures was determined with Cooper wheel tracker test. The wheel tracker system which is used for prediction of rut performance of bituminous mixture was created by repetitive wheel passes. The test was used to study the rut resistance of bituminous mixture at standard condition of load, temperature and at standard condition speed. The results of rut resistance cab be work out from rate of rutting during test and rut depth was obtained by using Linear Variable Displacement Transformer (LVDT). Cooper wheel tracker load assembly js shown in Fig 6.

\section{RESULTS AND DISCUSSION}

\subsection{Rut Performance of Mixes}

The rut performance of neat and modified asphalt 
mixtures was determined with Cooper wheel tracker test. The wheel tracker system which is used for prediction of rut performance of bituminous mixture created by repetitive wheel passes. The test was used to study the rut resistance of bituminous mixture at standard condition of load, temperature and at standard condition speed. The results of rut resistance cab be work out from rate of rutting during test and rut depth was obtained by using linear variable displacement transformer (LVDT). Cooper wheel tracker load assembly are shown in the Fig 6.

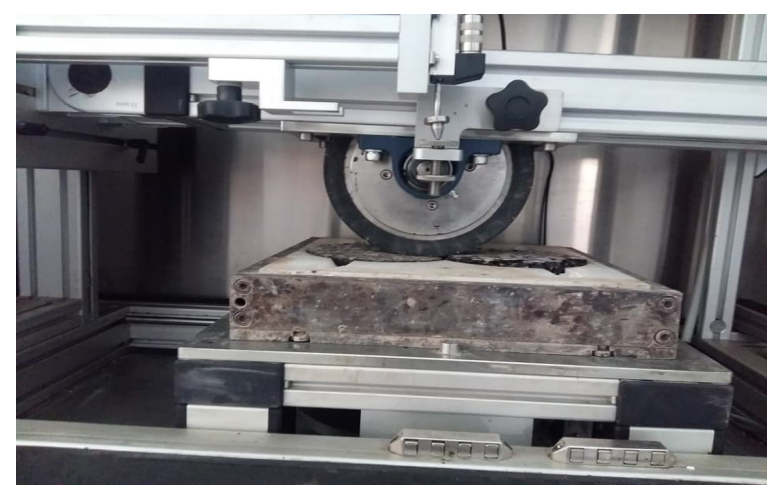

Fig. 6: Loaded Wheel Tracker

The samples were tested at $55^{\circ} \mathrm{C}$. The test was conducted according to EN 12697-22. Three replicates were used for each mixture. The obtained results are given in Fig 7.

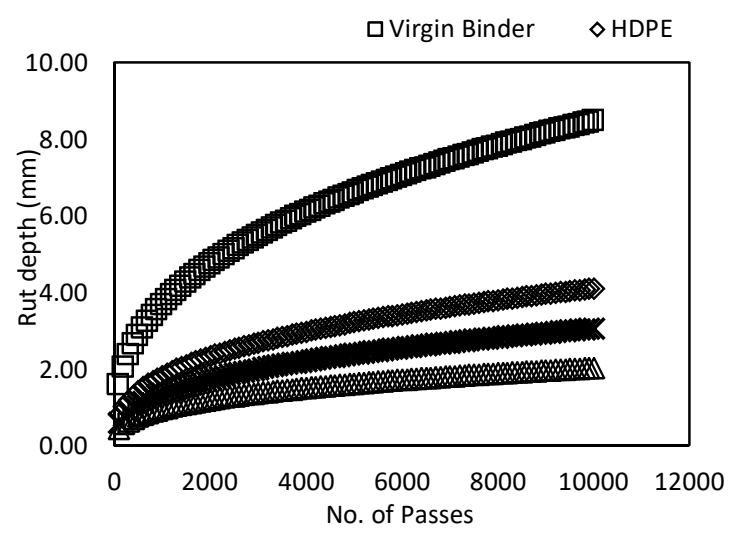

Fig. 7: Copper Wheel Tracker Test Results

Fig. 7 shows the deformation curve of modified mixtures. Rut depth which is measured in millimeter $(\mathrm{mm})$ was plotted as ordinate while number of wheel passes were plotted as abscissa. It has been observed that plastomers modified mixture performed better as compared to virgin mixture. In plastomers, polyethylene terephthalate has maximum resistance against rutting and improve up to $70 \%$ resistance Mehran University Research Journal of Engineering and Technology, Vol. 40, No.3, July 2021 [p-ISSN: 0254-7821, e-ISSN: 2413-7219] against rutting. As from previous studies, [21] reported that asphalt mixture modification with polymers, improve stiffness as well as temperature susceptibility of the mixture, which, in turn, decreases the rut depth of asphalt mixture which is common issue in high temperature area. The result shows that none of the tested specimen has reached at its failure rut value of $12.5 \mathrm{~mm}$ at 10,000 wheel passes.

\subsection{Dynamic Modulus Test}

It is a linear viscoelastic test which is used for the determination of complex dynamic modulus $\left|E^{*}\right|$. The $\left|\mathrm{E}^{*}\right|$ is a stress-strain relationship of linear viscoelastic material under a sinusoidal loading condition. Dynamic modulus is a component which is used for the estimation of stiffness of bituminous material at a given frequency and temperature condition. Neat and modified asphalt mixtures in replicates were tested at standard condition of frequency and temperature. The obtained date such as $\left|E^{*}\right|$ and phase angle which describe the visco-elastic behavior of material were used for development of master curve. The master curve simulates pavements with different possible loading as well as climate conditions. In development of master curve, time-temperature superposition principles were used. In time-temperature superposition principle, all data of various frequencies and temperature should be shifted to a reference temperature and get a single curve which is known as $\left|\mathrm{E}^{*}\right|$ master curve. For each modifier, three replicates (100 $\mathrm{mm}$ in diameter with $150 \mathrm{~mm}$ in height) were tested at various temperature $(4.4,21.1,37.8$ and $54.4^{\circ} \mathrm{C}$ ) with sweep of frequencies (25 to $0.1 \mathrm{~Hz}$ ). A master curve was developed at reference temperature of $21^{\circ} \mathrm{C}$ which is shown in Fig. 8. The test was conducted in accordance with AASHTO TP 62. Dynamic modulus $|\mathrm{E} *|$ was plotted at ordinate and reduced frequency was plotted on abscissa.

Fig 8 shows that polyethylene terephthalate modified mixes have higher modulus at low temperature and high frequency condition as compared to other plastomers but low density polyethylene have more modulus values at other end of the curve which denote high temperature and low frequency condition. The results indicate that polyethylene terephthalate modified mixes have stiff behavior at low temperature condition. 


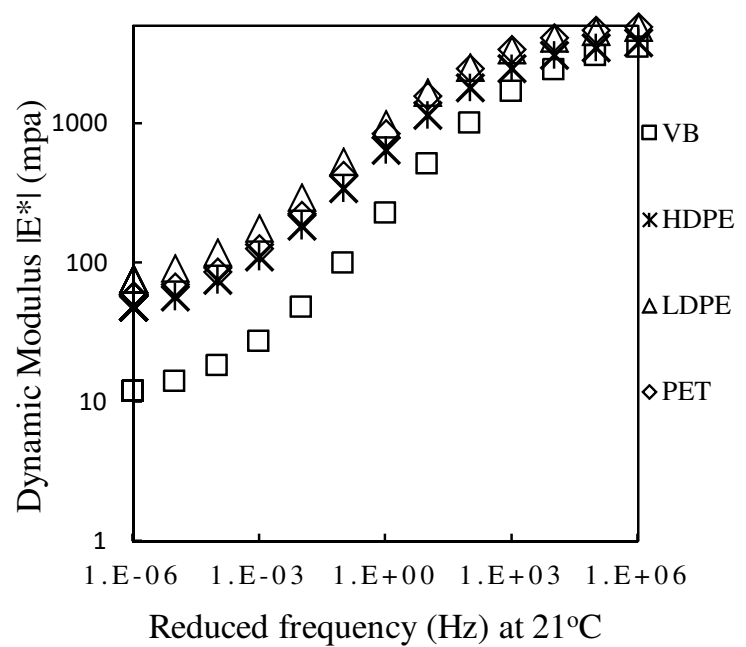

Fig. 8: Master curve of neat and modified Asphalt mixes

\subsection{Creep Performance of Mixes}

Creep performance test has performed in Universal Testing Machine (UTM) which is a closed loop control testing device which is used for asphalt material testing. UTM transmit energy to the sample with high pressure through double sided piston. For creep performance test by UTM, a repeated load of definite magnitude with a definite cyclic duration was applied to the sample. In this test, strain correlates with permanent deformation which simulate to the rutting in the field. In this study, conditioning stress and time of $10 \mathrm{kPa}$ and 100 second respectively, were applied. Similarly, a pulse loading of 3600 cycles at $500 \mathrm{kpa}$ stress condition with pulse width of 500 milli-seconds and pulse period of 2000 milli-second were applied. Results obtained from this test are given in Fig. 9.

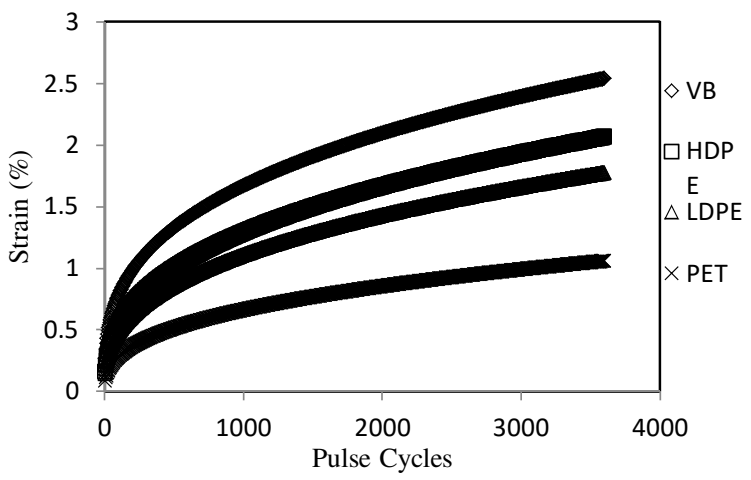

Fig. 9: Strain (\%) of modified asphalt mixes

In Fig. 9, accumulated strain was taken on primary ordinate and pulse cycles were taken on abscissa. The result shows that polyethylene terephthalate has minimum strain at high temperature. The sequence of performance is polyethylene terephthalate, then low density polyethylene, high density polyethylene and virgin binder has maximum strain.

\subsection{Fatigue Performance of Mixes}

Fatigue performance of the asphalt mixture was measured with four-point bending beam test. The test was used to measure the deterioration of HMA due to loss of stiffness. Fatigue is helpful parameter in designing purpose of flexible pavements. These descriptions were useful for providing fatigue life of HMA layer under repeated traffic loading. The test was conducted in accordance with AASHTO T 321. The test was performed in stress control mode. The test was used for the measurement of fatigue life and energy of $380 \mathrm{~mm}$ long with $50 \mathrm{~mm}$ thick and $63 \mathrm{~mm}$ wide asphalt beam sample. The temperature of the chamber was maintained at $20 \pm 0.5^{\circ} \mathrm{C}$. The beam was considered as failure, when there is $50 \%$ reduction occurred in initial stiffness of the beam. The obtained results are given in Fig. 10.

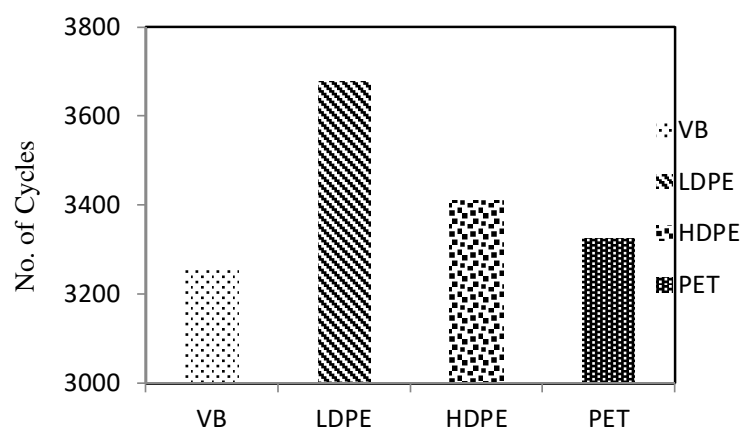

Fig. 10: Fatigue performance of asphalt mixture

It can be observed from Fig 10, low density polyethylene modified mixes have maximum resistance against fatigue cracking. Although all plastomers improve fatigue life, LDPE has more effect on fatigue life as compared to other plastomers. The overall performance of each modified asphalt mixtures are given in Fig 11-13.

Fig. 11 shows the improvement in performances due to polyethylene terephthalate. PET has considerable effect on rut resistance, dynamic modulus and creep performance. 


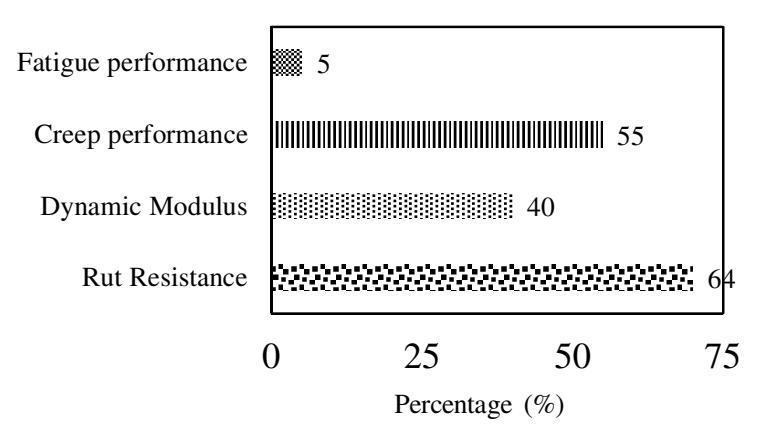

Fig. 11: Percent Improvement in Performances due to PET

Fig. 12 shows the improvement in performance of asphalt mixture due to low density polyethylene. LDPE increases rut resistance, dynamic modulus and creep performance to that of neat binder. LDPE also has a considerable effect on fatigue performance of the mixture.

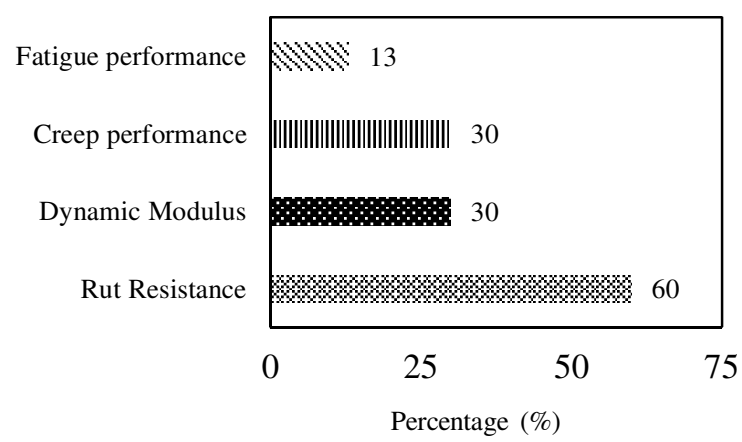

Fig. 12: Percent improvement in performances due to LDPE

Fig. 13 shows the improvement in performances due to high density polyethylene. HDPE also increases rut resistance and creep performance but its improvement in dynamic modulus is lower than other plastomers. HDPE also increase fatigue performance of the asphalt mixture up $7 \%$ to that of neat binder.

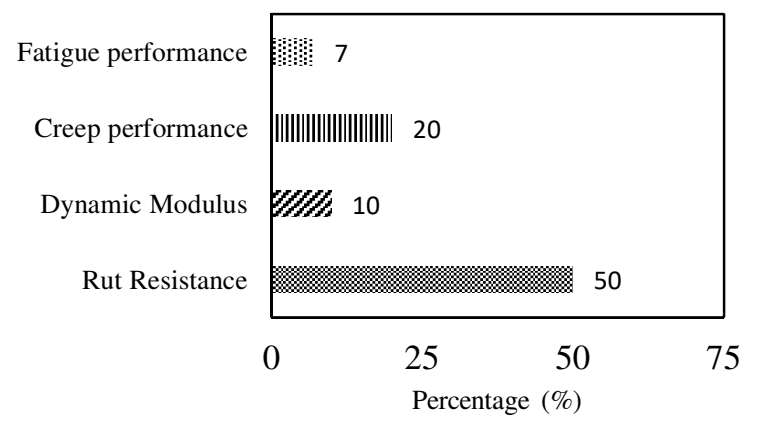

Fig. 13: Percent Improvement in performances due to HDPE

\section{CONCLUSIONS}

The aim of this research study was to evaluate the effect of plastomer modifiers on performance of asphalt mixture and also provide performance ranking of different plastomers at high/low temperature. Based on all laboratory test results it can be concluded that,

(i) Plastomer modified asphalt mixture enhances the viscoelastic behavior of asphalt mixtures and provides harder, stiff and flexible pavements.

(ii) The plastomer such as polyethylene terephthalate has greater influence on asphalt mixture at high temperature as compared to other plastomers. It improves the rut resistance up to $70 \%$ to that of conventional asphalt mixtures.

(iii) The plastomer such as high-density polyethylene improves rut resistance up to $50 \%$ to that of conventional asphalt mixture.

(iv) The plastomer such as low-density polyethylene improves rut resistance up to $60 \%$ and fatigue performance up to $13 \%$ to that of conventional asphalt mixture.

\section{RECOMMENDATION}

It can be recommended that use the polyethylene terephthalate in high temperature areas perform better as compared to LDPE and HDPE. The result of polyethylene terephthalate shows maximum values against rut resistance and creep performance at high temperature condition. While high density polyethylene and low density polyethylene in intermediate temperature areas are efficient and economical blends of asphalt mixture as they enhance the performance life.

\section{ACKNOWLEDGEMENTS}

The authors are thankful to Taxila Institute of Transportation Engineering for providing the friendly environment for research work.

\section{REFERENCES}

1. Airey G., "Rheological evaluation of ethylene vinyl acetate polymer modified bitumens", Construction and Building Materials, Vol. 16, No. 8, pp. 473-487, 2002. 
2. Masad E., Huang C.-W., Airey, G., and Muliana, A., "Nonlinear Viscoelastic Analysis of Unaged and Aged Asphalt Binders", Construction and Building Materials, Vol. 22, No. 11, pp. 21702179, 2008.

3. Mandula J., Olexa T, "Study of the visco-elastic parameters of asphalt concrete", Procedia Engineering, Vol. 190, pp. 207-214, 2017.

4. Wang J, Molenaar A.A., Van de Ven F.M, Wu S, "Influence of internal structure on the permanent deformation behavior of a dense asphalt mixture", Construction and Building Materials, Vol. 171, pp. 850-857, 2018.

5. Pérez-Lepe A., Martınez-Boza F., Gallegos C., González O., Munoz M, Santamarıa A, "Influence of the processing conditions on the rheological behaviour of polymer-modified bitumen $\boldsymbol{r}^{2}$ ", Fuel, Vol. 82, No. 11, pp. 1339-1348, 2003.

6. González O., "Rheological Techniques as a Tool To Analyze Polymer- Bitumen Interactions: Bitumen Modified with Polyethylene and Polyethylene-Based Blends", Energy and Fuels, Vol. 16, No. 5, pp. 1256-1263, 2002.

7. Kok B.V., Yilmaz. M., "The effects of using lime and styrene-butadiene-styrene on moisture sensitivity resistance of hot mix asphalt", Construction and Building Materials, Vol. 23, No. 5, pp. 1999-2006, 2009.

8. Cong L., Peng J., Guo Z., Wang Q., "Evaluation of fatigue cracking in asphalt mixtures based on surface energy", Journal of Materials in Civil Engineering, Vol. 29, No. 3, 2017.

9. Nciri N., Kim N., Cho N., "New insights into the effects of styrene-butadiene-styrene polymer modifier on the structure, properties, and performance of asphalt binder: The case of AP-5 asphalt and solvent deasphalting pitch", Materials Chemistry and Physics, Vol. 193, pp. 477-495, 2017.

10. Kalantar Z.N., Karim M.R., Mahrez A., "A review of using waste and virgin polymer in pavement," Construction and Building Materials, Vol. 33, pp. 55-62, 2012.

11. Gautam P.K., Kalla P., Jethoo A.S., Agrawal R., Singh H., "Sustainable use of waste in flexible pavement: A review", Construction and Building Materials, Vol. 180, pp. 239-253, 2018.

12. Bansal S., Misra A. K., Bajpai P., "Evaluation of modified bituminous concrete mix developed using rubber and plastic waste materials," International Journal of Sustainable Built Environment, Vol. 6, No. 2, pp. 442-448, 2017.

13. El-Naga. I. A. and Ragab. M, "Benefits of utilization the recycle polyethylene terephthalate waste plastic materials as a modifier to asphalt mixtures," Construction and Building Materials, vol. 219, pp. 81-90, 2019.

14. Ragaert K., Delva L., Van Geem K., "Mechanical and chemical recycling of solid plastic waste", Waste Management, Vol. 69, pp. 24-58, 2017.

15. Movilla-Quesada M., Raposeiras A., Silva-Klein L., Lastra-González P., Castro-Fresno D., "Use of plastic scrap in asphalt mixtures added by dry method as a partial substitute for bitumen", Waste Management, Vol. 87, pp. 751-760, 2019.

16. Gibreil H. A., Feng C. P., "Effects of high-density polyethylene and crumb rubber powder as modifiers on properties of hot mix asphalt," Construction and Building Materials, Vol. 142, pp. 101-108, 2017.

17. Kumar P., Chandra S., Bose S., "Laboratory investigations on SMA mixes with different additives," International Journal of Pavement Engineering, Vol. 8, No. 1, pp. 11-18, 2007.

18. Taylor A. M., "Genomic and functional approaches to understanding cancer aneuploidy," Cancer cell, Vol. 33, No. 4, pp. 676-689. e3, 2018.

19. Appiah J. K., Berko-Boateng V. N., Tagbor. T. A, "Use of waste plastic materials for road construction in Ghana", Case Studies in Construction Materials, vol. 6, pp. 1-7, 2017.

20. Shao Y., "Advances in molecular quantum chemistry contained in the Q-Chem 4 program package", Molecular Physics, Vol. 113, No. 2, pp. 184-215, 2015.

21. Formela K., Sulkowski M., Saeb M. R., Colom X., Haponiuk J. T., "Assessment f microstructure, physical and thermal properties of bitumen modified with LDPE/GTR/elastomer ternary blends", Construction and Building Materials, Vol. 106, pp. 160-167, 2016.

22. Attaelmanan M., Feng C. P., Al-Hadidy A., "Laboratory evaluation of HMA with high density polyethylene as a modifier," Construction and Building Materials, Vol. 25, No. 5, pp. 27642770, 2011.

Mehran University Research Journal of Engineering and Technology, Vol. 40, No.3, July 2021 [p-ISSN: 0254-7821, e-ISSN: 2413-7219] 
23. Vamegh M., Ameri M., Naeni S. F. C., "Performance evaluation of fatigue resistance of asphalt mixtures modified by SBR/PP polymer blends and SBS", Construction and Building Materials, Vol. 209, pp. 202-214, 2019.

24. Hafeez I., Kamal M., Ishaq M., Ahmad N., Khanzada S., "A Laboratory-Based Research Study to Investigate the Aggregate Packing Characteristics and Its Influence on Asphaltic Mixture's Performance", Arabian Journal for Science and Engineering, Vol. 40, No. 11, pp. 3119-3134, 2015.

25. Ranieri M., Celauro C., "Improvement of high modulus asphalt mixtures with average quality aggregate and bitumen by application of polymeric additives", Construction and Building Materials, Vol. 178, pp. 183-194, 2018.
26. Greencompletely.com. Garbage and Recycling: Recyclable Materials: Plastic: Table of Properties. Available: http://greencompletely.com/garandrec/materials/r ecymat01plasttabl.php

27. Ahmadinia E., Zargar M., Karim M. R., Abdelaziz M., Shafigh P., "Using waste plastic bottles as additive for stone mastic asphalt", Materials and Design, Vol. 32, No. 10, pp. 48444849, 2011. 